\title{
Relationship between sleep disturbances and addiction
}

\author{
Khurshid A Khurshid* \\ Department of Psychiatry, University of Florida, Gainesville, Florida, USA
}

\begin{abstract}
Sleep disturbances particularly insomnia is a common harbinger of addiction. Insomnia is often times seen as a symptom of substance use disorder. Insomnia can persist after successful recovery and remission. It may put individuals at risk of relapse.

Recognition of sleep disturbances and their treatment by incorporating sleep promoting strategies can lead to better outcomes. This review highlights the relationship between sleep disturbances and addiction. It also provides insights into management strategies.
\end{abstract}

\section{Introduction}

Sleep disturbance is a risk factor for substance use disorder. There is a bi-directional relationship between sleep disturbances and substance use [1]. Sleep disturbances in adolescents who do not have substance use disorders are associated with future development of substance abuse $[2,3]$. Sleep disorders are common in patients with addictive disorders. Mahfoud et al. (2009) described that significant number of patients with addictive disorders had sleep disorders. The most common sleep disorders were Insomnia, Sleep apnea and Restless leg syndrome [4]. This review elucidates the relationship of sleep disturbances and substance use.

Various substances of abuse are associated with a number of sleep disorders, including insomnia, daytime sleepiness, parasomnia, and sleep apnea [5]. A significant number of patients who abuse alcohol have sleep disturbances [5]. Other substances of abuse like marijuana, nicotine, caffeine, and cocaine, can also lead to sleep disturbances. These substances disrupt the normal complex mechanisms involved in initiation and maintenance of healthy sleep. They cause disruption in a number of neurotransmitter systems including acetylcholine, dopamine, gamma-aminobutyric acid (GABA), glutamate, norepinephrine, and orexin [6].

Here we summarize the sleep disturbances caused by specific substances of abuse.

\footnotetext{
Alcohol

Alcohol intake hastens sleep onset but it leads to fragmented sleep during the rest of the night [7]. Chronic alcohol use leads to prolonged sleep latency, overall decrease in sleep time, decreased sleep efficiency, decreased rapid eye movement (REM) sleep, difficulty maintaining sleep, early morning awakenings, nonrestorative sleep and fatigue [8]. Acute alcohol use is associated with a decrease in total Rapid Eye movement (REM) sleep, especially in the first half of the night, and with an associated prolongation in REM onset latency. Figures 1,2 shows effects of chronic alcohol use in patients with alcohol use disorder [9].

People also commonly use alcohol as a sleep aid. The above figure also shows that habitual use of alcohol as a self -medication for sleep problems is a risk factor for alcohol addiction. It also shows that persistent sleep disturbances in abstinence is a risk factor for relapse.
}

Insomnia is commonly seen in patients with alcoholism and rates range from $36 \%$ to $91 \%$ in patients admitted for treatment of alcoholism [10]. It is noteworthy that insomnia may persist even after weeks or months of abstinence from alcohol [8]. This is very important finding and it may put patients who are recovering from alcohol at risk of relapse. Patients suffering from insomnia are at twice the risk of developing alcohol-related problems. Sleep disturbances that persist in the recovery process, may be associated with comorbid depression [8].

Alcohol may also cause increased upper airway resistance and snoring even in people with no previous history of obstructive sleep apnea (OSA) [11]. This increased predilection for OSA persists even after abstinence of 3 to 6 weeks. This could lead to increased daytime sleepiness in addition to disturbed sleep in patients with chronic alcoholism. Sleep disturbances are commonly seen in alcohol withdrawal and include hyperarousal and jitteriness with short, fragmented sleep episodes and rebound in REM sleep [11]. In severe withdrawal and delirium tremens (DTs), total sleep duration is significantly curtailed, sleep is fragmented, and REM sleep may be increased $[12,13]$.

\section{Marijuana}

Marijuana has shown to improve sleep onset subjectively; however, polysomnographic studies do not support this effect [14,15]. Marijuana may slightly increase stage N3 sleep during acute use, but decrease stage N3 sleep with chronic use and withdrawal [16]. Marijuana use also leads to changes in REM sleep, with a decrease in overall REM percentage during acute use and increase in REM percentage during withdrawal [17]. Abrupt discontinuation from heavy marijuana use can lead to poor sleep quality and contribute to early relapses. Vandrey et al. [17] reported that extended-release zolpidem showed beneficial effects on sleep when administered during cannabis withdrawal. The study suggests that using hypnotics during cannabis withdrawal may be a useful adjunctive strategy in the treatment of cannabis use disorders; however, zolpidem has significant potential for abuse.

${ }^{*}$ Correspondence to: Khurshid A Khurshid, MD, FAASM, FAPA, Department of Psychiatry, University of Florida, Gainesville, Florida, USA, Tel: (352)594-1865; E-mail: kakhurshid@yahoo.com

Received: July 22, 2018; Accepted: July 24, 2018; Published: July 27, 2018 


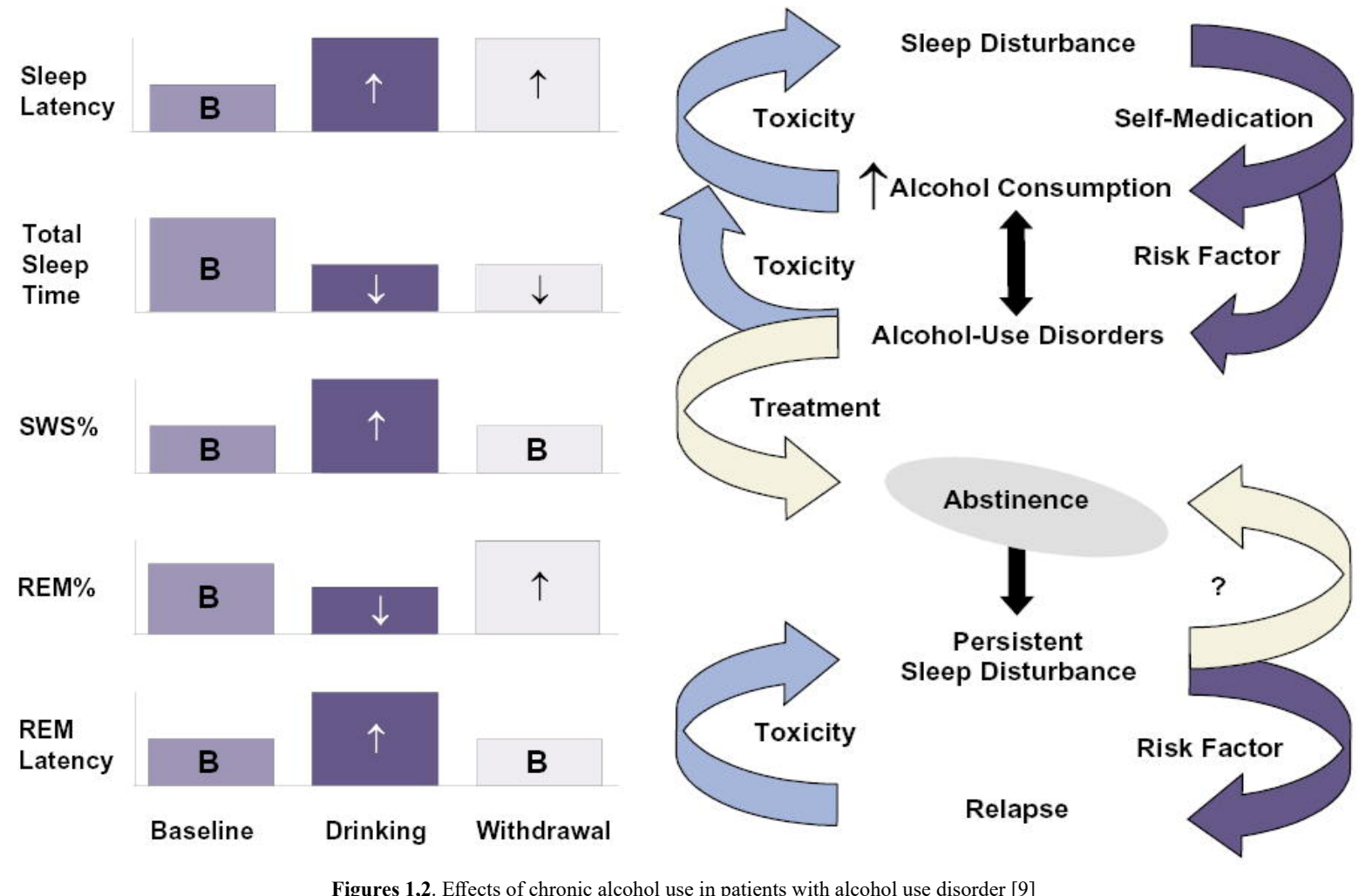

\section{Opioids}

Opioids can cause changes in sleep architecture during the intoxication and withdrawal. Sleep problems are seen during treatment with opiates in induction, maintenance, and abstinence phases of use [18]. During the induction phase, there is a decrease in REM sleep and stage N3 sleep, and an increase in wakefulness and arousals. Sleep efficiency and total sleep time are decreased, and stage N2 and REM latency are increased. Sleep problems particularly insomnia is seen in opiate withdrawal. There also decrease in REM percentage sleep during opioid withdrawal. Long-term abstinence can lead to increase in total sleep time and a rebound in stage N3 sleep and REM percentage. A significant number of patients (up to $80 \%$ ) on methadone maintenance treatment have sleep problems. Chronic opioid use can also lead to central sleep apnea (CSA) and CSA is seen in up to $30 \%$ of patients on Methadone maintenance treatment [19]. Walker et al. [20] found a dose-related and independent relationship between chronic opioid use and CSA.

\section{Cocaine and other stimulants}

Sleep disturbances are common during cocaine intoxication and withdrawal, including insomnia and hypersomnolence. Sleep disturbances tend to normalize in about 1 week [21]. However, there may be persistent and progressive sleep disturbances in cocaine abstinence [22,23].

Persistent Sleep disturbances during prolonged periods of abstinence from cocaine and can cause relapse to cocaine use [23]. Therefore, monitoring for sleep disturbance and improving sleep quality should be a clinical focus during abstinence and recovery [24,25].

Amphetamine and related stimulants increase dopamine release. During acute administration, $\mathrm{d}$-amphetamine can cause a decrease

in total sleep time and sleep efficiency as well as an increase in sleep latency and the number of awakenings. During the withdrawal phase, there is a decrease in sleep latency, an increase in total sleep time and sleep efficiency [25].

\section{Caffeine and nicotine}

Caffeine is activating. The effects of caffeine usually lasts in our system for about 6 hours. Acute caffeine administration close to bedtime can lead to an increase in sleep latency, a decrease in total sleep time, and decrease in stage N3 sleep [26].

There is some evidence that caffeine intake earlier in the day can affect sleep during the coming night by decreasing total sleep time and sleep efficiency. Caffeine withdrawal may lead to increased sleep latency [26].

Nicotine has direct and indirect effects on sleep through several different mechanisms [27]. Nicotine withdrawal during sleep, leading to sleep disruption [28]. Smoking also leads to several medical problems including chronic obstructive lung disease, which can also disrupt sleep and affect sleep architecture. Smokers experience difficulty initiating and maintaining sleep and are more dissatisfied with the quality of their sleep. Polysomnographic studies show that nicotine increases sleep latency, decreases total sleep time and decreases slow wave sleep [29]. Nicotine can also cause nightmares and disturbed sleep.

Nicotine withdrawal can lead to poor sleep quality and increased nightly awakenings [28]. In general patients should avoid excessive caffeine use and limit any caffeine intake to mornings only.

\section{Practical considerations}

Sleep disturbances are common in addictive disorders. Treatment of sleep disorders includes both pharmacologic and non-pharmacologic 
modalities. Addiction Treatment and Rehabilitation programs for substance use disorders should incorporate evaluation and treatment of sleep disturbances. Mere assumption that a focus on achieving and maintaining sobriety will restore natural sleep patterns may put patients at disadvantage and increased risk of relapse. Research has shown that sleep disturbances, such as insomnia, continue to persist during recovery and are significant risk factors for relapse. Pharmacologic options for treatment of sleep disturbances in relation to substance use disorder have been limited. Sedative-hypnotic medications are best avoided given their high abuse potential, especially in patients with alcoholism However with the advent of new classes of medications like melatonin agonists, orexin antagonists, there is potential role of these medications in addictive disorders. Sedative antidepressant medications may be a good option for patients who have comorbid depression, including the tricyclic antidepressants amitriptyline and doxepin, but caution needs to be exercised when using these because these can lead to life-threatening arrhythmias if taken in overdose [30]. Mirtazapine is an antidepressant that has antihistaminic sedating properties at lower doses and has demonstrated efficacy in patients with alcohol use disorder and comorbid depression. However, no randomized controlled trials are available that have evaluated the role of mirtazapine as a sleep aid in patients with substance use. Among antidepressants, trazodone seems to have the best support in the literature for treatment of insomnia in alcoholism. Gabapentin has been shown to sleep promoting effects particularly in alcoholism [31]. Melatonin has a role in the regulation of sleep-wake cycle. Melatonin circadian rhythm dysregulation has been shown to oocur in patients with chronic alcoholism [32,33]. Ramelteon, which acts as an agonist at central nervous system melatonin receptors, has shown beneficial effects in improving insomnia and total sleep time and decreasing sleep-onset latency in small number of patients [34].

The non-pharmacologic interventions employed in the treatment of insomnia include cognitive-behavioral therapy for insomnia (CBTi) [35]. CBTi has been shown to be effective in patients during recovering from alcoholism [35,36].

\section{Conclusion}

Sleep disturbances are commonly in addictive disorders in various phases of addiction. Sleep disturbances can complicate the course of recovery from substance use. Strategies that target sleep disturbance become an integral part of recovery programs, including non-pharmacologic and pharmacologic options. The evaluation and treatment of sleep disturbances is important in fostering recovery and preventing relapse. There is need for research on developing sleep promoting agents that have low abuse potential and can specifically target aspects of sleep that are disturbed by substance use.

\section{References}

1. Ara A, Jacobs W, Bhat IA, McCall WV (2016) Sleep disturbances and substance use disorders. A Bi-directional relationship. Psychiatric Annals 46: 408-412.

2. Wong MM, Brower KJ, Fitzgerald HE, Zucker RA (2004) Sleep problems in early childhood and early onset of alcohol and other drug use in adolescence. Alcohol Clin Exp Res 28: 578-587. [Crossref]

3. Wong M, Brower K, Nigg J, Zucker R (2010) Childhood sleep problems, response inhibition, and alcohol and drug outcomes in adolescence and young adulthood. Alcohol Clin Exp Res 34: 1033-1044. [Crossref]

4. Mahfoud Y, Talih F, Streem D, Budur K (2009) Sleep disorders in substance abusers: how common are they? Psychiatry (Edgmont) 6: 38-42. [Crossref]

5. Schierenbeck T, Riemann D, Berger M, Hornyak M (2008) Effect of illicit recreational drugs upon sleep: cocaine, ecstasy and marijuana. Sleep Med Rev 12: 381-389. [Crossref]
6. Cohn TJ, Foster JH, Peters TJ (2003) Sequential studies of sleep disturbance and quality of life in abstaining alcoholics. Addict Biol 8: 455-462. [Crossref]

7. Currie SR, Clark S, Rimac S, Malhotra S (2003) Comprehensive assessment of insomnia in recovering alcoholics using daily sleep diaries and ambulatory monitoring. Alcohol Clin Exp Res 278: 1262-1269. [Crossref]

8. Wallen GR, Brooks AT, Whiting B, Clark R, Krumlauf MC, et al. (2014) The prevalence of sleep disturbance in alcoholics admitted for treatment: a target for chronic disease management. Fam Community Health 37: 288-297. [Crossref]

9. Brower KJ (2001) Alcohol's effects on sleep in alcoholics. Alcohol Res Health 25: 110-125. [Crossref]

10. Ebrahim IO, Shapiro CM, Williams AJ, Fenwick PB (2013) Alcohol and sleep I: effects on normal sleep. Alcohol Clin Exp Res 37: 539-549. [Crossref]

11. Brower KJ (2001) Alcohol's effects on sleep in alcoholics. Alcohol Res Health 25: 110-125. [Crossref]

12. Landolt HP, Gillin JC (2001) Sleep abnormalities during abstinence in alcoholdependent patients. Aetiology and management. CNS Drugs 15: 413-425. [Crossref]

13. Nakazawa Y, Yokoyama T, Koga Y, Kotorii T, Ohkawa T, et al. (1981) Polysomnographic study of terminal sleep following delirium tremens. Drug Alcohol Depend 8: 111-117. [Crossref]

14. Feinberg I, Jones R, Walker JM, Cavness C, March J (1975) Effects of high dosage delta-9-tetrahydrocannabinol on sleep patterns in man. Clin Pharmacol Ther 17: 458 466. [Crossref]

15. Barratt ES, Beaver W, White R (1974) The effects of marijuana on human sleep patterns. Biol Psychiatry 8: 47-54. [Crossref]

16. Bolla KI, Lesage SR, Gamaldo CE, Neubauer DN, Funderburk FR, et al. (2008) Sleep disturbance in heavy marijuana users. Sleep 31: 901-908. [Crossref]

17. Vandrey R, Smith MT, McCann UD, Budney AJ, Curran EM (2011) Sleep disturbance and the effects of extended-release zolpidem during cannabis withdrawal. Drug Alcohol Depend 117: 38-44. [Crossref]

18. Wang D, Teichtahl H (2007) Opioids, sleep architecture and sleep-disordered breathing Sleep Med Rev 11: 35-46. [Crossref]

19. Sharkey KM, Kurth ME, Anderson BJ, Corso RP, Millman RP, et al. (2011) Assessing sleep in opioid dependence: a comparison of subjective ratings, sleep diaries, and home polysomnography in methadone maintenance patients. Drug Alcohol Depend 113: 245 248. [Crossref]

20. Walker JM, Farney RJ, Rhondeau SM, Boyle KM, Valentine K, et al. (2007) Chronic opioid use is a risk factor for the development of central sleep apnea and ataxic breathing. J Clin Sleep Med 3: 455-461. [Crossref]

21. Johanson CE, Roehrs T, Schuh K, Warbasse L (1999) The effects of cocaine on mood and sleep in cocaine-dependent males. Exp Clin Psychopharmacol 7: 338-346. [Crossref]

22. Watson R, Bakos L, Compton P, Gawin F (1992) Cocaine use and withdrawal: the effect on sleep and mood. Am J Drug Alcohol Abuse 18: 21-28. [Crossref]

23. Trksak GH, Bracken BK, Jensen JE, Plante DT, Penetar DM, et al. (2013) Effects of sleep deprivation on brain bioenergetics, sleep, and cognitive performance in cocainedependent individuals. ScientificWorldJournal 2013: 947879. [Crossref]

24. Pace-Schott EF, Stickgold R, Muzur A, Wigren PE, Ward AS, et al. (2005) Sleep quality deteriorates over a bingeabstinence cycle in chronic smoked cocaine users. Psychopharmacology (Berl) 179: 873-883. [Crossref]

25. Ogeil RP, Phillips JG (2015) Commonly used stimulants: sleep problems, dependence and psychological distress. Drug Alcohol Depend 153: 145-151. [Crossref]

26. Landolt HP, Werth E, Borbély AA, Dijk DJ (1995) Caffeine intake (200 mg) in the morning affects human sleep and EEG power spectra at night. Brain Res 675: 67-74. [Crossref]

27. Zhang L, Samet J, Caffo B, Punjabi NM (2006) Cigarette smoking and nocturnal sleep architecture. Am J Epidemiol 164: 529-537. [Crossref]

28. Wetter DW, Fiore MC, Baker TB, Young TB (1995) Tobacco withdrawal and nicotine replacement influence objective measures of sleep. J Consult Clin Psychol 63: 658-667. [Crossref]

29. Jaehne A, Loessl B, Barkai Z, Riemann D, Hornyak M (2009) Effects of nicotine on sleep during consumption, withdrawal and replacement therapy. Sleep Med Rev 13: 363-377. [Crossref]

30. Cornelius JR, Douaihy AB, Clark DB, Daley DC, Chung TA, et al. (2013) Mirtazapine in Comorbid Major Depression and Alcohol Use Disorder: A Long-Term Follow-Up Study. J Addict Behav Ther Rehabil 3: 1560. [Crossref] 
31. Gentry JR, Hill C, Malcolm R (2002) New anticonvulsants: a review of applications for the management of substance abuse disorders. Ann Clin Psychiatry 14: 233-245. [Crossref]

32. Kuhlwein E, Hauger RL, Irwin MR (2003) Abnormal nocturnal melatonin secretion and disordered sleep in abstinent alcoholics. Biol Psychiatry 54: 1437-1443. [Crossref]

33. Conroy DA, Hairston IS, Arnedt JT, Hoffmann RF, Armitage R, et al. (2012) Dim light melatonin onset in alcohol-dependent men and women compared with healthy controls. Chronobiol Int 29: 35-42. [Crossref]
34. Brower KJ, Conroy DA, Kurth ME, Anderson BJ, Stein MD (2011) Ramelteon and improved insomnia in alcohol-dependent patients: a case series. J Clin Sleep Med 7: 274-275. [Crossref]

35. Arnedt JT, Conroy D, Rutt J, Aloia MS, Brower KJ, et al. (2007) An open trial of cognitive-behavioral treatment for insomnia comorbid with alcohol dependence. Sleep Med 8: 176-180. [Crossref]

36. Brower KJ (2003) Insomnia, alcoholism and relapse. Sleep Med Rev 7: 523-539. [Crossref]

Copyright: (C2018 Khurshid KA. This is an open-access article distributed under the terms of the Creative Commons Attribution License, which permits unrestricted use, distribution, and reproduction in any medium, provided the original author and source are credited. 